\title{
A descriptive account of the Quebec French diphthong FÊTE
}

\author{
Josiane Riverin-Coutlée (i) \\ Département de langues, linguistique et traduction, \\ Faculté des lettres et des sciences humaines, Université Laval \\ \& Institute of Phonetics and Speech Processing, \\ Ludwig-Maximilians-Universität Munich \\ josiane.riverin-coutlee.1@ulaval.ca
}

Johanna-Pascale Roy

Département de langues, linguistique et traduction,

Faculté des lettres et des sciences humaines, Université Laval

johanna-pascale.roy@lli.ulaval.ca

Diphthongization has a long history in Quebec French. In this variety, lengthened vowels have the potential to be diphthongized. However, one vowel stands out, as it is always long and seems particularly inclined to be diphthongal: the FÊTE vowel. While it has been much studied over the years, some uncertainties remain in the literature, especially whether length or quality primarily distinguishes it and which phonetic transcription appropriately reflects the way Quebec French speakers pronounce it today. This study addresses these issues by drawing a parallel between acoustic properties of the FÊTE vowel and those of other vowels produced in similar consonantal contexts by 52 native speakers of Quebec French. After analyzing 8866 tokens, we present a descriptive account of their relative duration, location in F1/F2 planes and spectral changes. The results show that FÊTE is, in fact, acoustically distinct, but more in terms of the spectral changes that occur than its duration. Its first two formants extensively shift between $25 \%$ and $75 \%$ of its duration, with a substantial F2 increase and F1 decrease. In F1/F2 planes, FÊTE has onset values similar to /a/ and offset values similar to $/ \varepsilon /$. Therefore, we argue that the two most commonly used phonological transcriptions for this singular vowel, $/ 3 /$ and $/ \varepsilon: /$, present some problems and do not capture its characterizing features. Drawing on our results and the IPA vowel chart, we suggest a more accurate symbol.

\section{Introduction}

French vowels are reputedly pure, that is, non-diphthongal (Delattre 1963). In their IPA illustration, Fougeron \& Smith (1993) list 14 vowels - 11 oral and 3 nasal - all of them monophthongs. At the acoustic level, Gottfried (1984) observes that French vowels in 
consonant-vowel-consonant (CVC) syllables are characterized by very short flanking consonantal transitions and a stable plateau in-between, as opposed to English vowels that present extensive formant dynamics (e.g. Nearey \& Assmann 1986). Additionally, according to Fougeron \& Smith (1993: 74), length contrasts in vowels are not phonologically relevant for 'most speakers' of French, including the Parisian speaker their illustration is based on. For example, the majority of French speakers the authors refer to would produce the following pairs of words identically, that is, with a monophthongal and short $[\varepsilon]$ :

$\begin{array}{lll}\text { faite 'done' } & \text { vs. } & \text { fête 'party' [frt] } \\ \text { saine 'sane' } & \text { vs. } & \text { scène 'stage' [scn] } \\ \text { belle 'beautiful' } & \text { vs. } & \text { bêle 'bleat' [bsl] }\end{array}$

However, as briefly acknowledged by Fougeron \& Smith (1993), variation does exist. Speakers from eastern France, Belgium and Switzerland may produce the second word of these pairs with a long vowel: [ $\varepsilon$ :] (see e.g. Walter 1982, Avanzi 2018).

When it comes to Quebec French, which will be the variety studied in this article, speakers also differentiate between these pairs of words, but there is no consensus on the actual basis of the contrast. Some researchers attribute this to length, like in the French spoken in eastern France, Belgium and Switzerland, though vowel quality and the diphthongal quality of the second vowel of these pairs (henceforth the FÊTE vowel) have also been suggested. Indeed, one of the main features that distinguish Quebec French from European varieties is the possibility for some vowels to be produced with a complex nucleus (see e.g. Dumas 1974, 1987; Santerre \& Millo 1978; Walker 1984), a process that FÊTE might be particularly inclined to undergo (Leblanc 2012). The first goal pursued in this article is thus to determine, with the help of up-to-date empirical data, which cue - length or quality - makes FÊTE most different from FAITE (the first vowel of the pairs), but also from the other vowels of Quebec French.

An important issue we have come across when conducting this research has to do with the multiplicity of symbols used to transcribe FÊTE. Phonetic transcriptions include [E:], [æ:], [ $\left.{ }^{\mathrm{a}} \varepsilon\right],\left[\mathrm{a}^{\mathrm{i}}\right],[\mathrm{ae}],[\mathrm{ej}],[\mathrm{aj}],[3],[3 e]$ and $\left[3^{\mathrm{j}}\right]$, to name but a few (Dumas 1974; Santerre 1974; Walker 1984; Martin 1995, 2002; Morin 2009; Côté 2010, 2012). However, this vowel has also been transcribed phonologically as / $/$ / (identically to FAITE), /3/ or / $\varepsilon$ : (e.g. Dumas 1974; Santerre 1974; Martin 1995, 1996). The second goal we pursue is thus to propose a transcription of FÊTE that is consistent with both our empirical data and the International Phonetic Alphabet.

In Section 2, we provide the readers with further details regarding diphthongization and vocalic length in Quebec French, as well as the phonological status of FÊTE. We also use this section to present the main conclusions drawn by a few authors who analyzed FÊTE acoustically (Santerre 1974, Martin 1995, Leblanc 2012, Côté \& Lancien 2019), as well as summarize the rationale for the most widely used phonological transcriptions of this vowel. Section 3 describes the methods used to reach our goals. Results are detailed in Section 4, while Section 5 puts them into perspective, in regards to both the literature and our goals.

\section{FÊTE in Quebec French}

As briefly mentioned in the Introduction, the diphthongal quality Quebec French vowels may acquire is a distinguishing feature of this variety (see Paradis \& Dolbec 1998 for an extensive listing of phonetic phenomena taking place in Quebec French). In fact, diphthongization had already been mentioned in early descriptions of Quebec French, for example by Squair (1888: 162-165), who alternatively comments on 'a tendency to drawl' and 'real diphthong[s]'. While the reasons behind the emergence of this phenomenon in Quebec though not in Europe 
are unclear (Paradis \& Dolbec 1998), researchers agree that diphthongization is closely tied to duration.

First, let us recall that duration is an acoustic property of vowels correlated to their perceived length. In some languages and dialects, duration is used as a phonological contrast between same-quality vowels, while it may also vary contextually and depend on such factors as neighboring consonants, syllable type, stress, word or syntactic structure or speech rate. As for diphthongization, it basically consists of producing a vocalic nucleus with a double quality (or triple, in the case of triphthongs). Like duration, it may be involved in phonological contrasts or simply be a contextually driven event. In Quebec French, vowels can be diphthongized when stressed (i.e. in the last syllable of a word) and of relatively long duration. The main factors leading to such a longer duration in stressed vowels are their own nature and that of the syllabic coda.

All stressed vowels see their duration lengthened when followed by the so-called 'length-

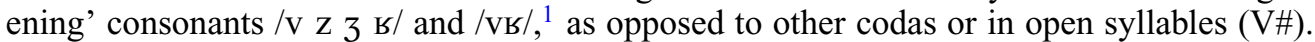
For example, /a/ is long in lave [la:v] 'lava', but not in lac [lak] 'lake' or la [la] 'the'. As for the naturally or historically long vowels, it is beyond the scope of this study to get into the in-depth discussions many authors have nurtured in the 20th century regarding the origins, evolution and distribution of vocalic length in (Quebec) French (e.g. Straka 1959, Martinet 1969, Morin \& Ouellet 1991, Yaeger-Dror 1994, Yaeger-Dror \& Kemp 1992), so let us simply mention that in closed syllables (e.g. CVC), /o ø a $\tilde{a} \tilde{\jmath} \tilde{\varepsilon} \tilde{\tilde{e}} /$ and FÊTE have a longer duration than other vowels (Côté 2010). For example, a word like saute 'jump' is pronounced with a long vowel, [so:t], while sotte [sot] 'stupid' or sept [set] 'seven' are not.

Once conditions conducive to diphthongization are created (i.e. stress and increased duration), complex vocalic nuclei that Quebec French speakers produce always rise and always remain on the same frontness/backness axis (Dumas 1974, Côté 2010). For example, saute 'jump' can be pronounced [soot] or [sout], but not * [sost] or *[soyt]. The diphthongization process admits few exceptions: only /a/ and some lexical items featuring the FAITE vowel cannot be diphthongized even if contextually lengthened (e.g. sage [sa:3] 'wise' or chèvre [ $\varepsilon: \mathrm{V} \zeta]$ 'goat'). Despite the apparent regularity of the diphthongization rule and the fact that it seems like a well-established practice in Quebec French (Squair 1888), it is usually not regarded as systematic. In particular, external factors such as socioeconomic background, geographical origin, age or formality make some speakers or communication situations more or less subject to diphthongization (Santerre 1974, Dumas 1987, Yaeger-Dror \& Kemp 1992, Martin 1995, Reinke 2005).

With regard to the foregoing, FÊTE seems to stand out. First, it is the only historically long vowel that does not have a short variant. Indeed, /o ø a $\tilde{\mathrm{a}} \tilde{\mathrm{o}} \tilde{\varepsilon} \tilde{\mathrm{e}} /$ are long in closed syllables, but short in open syllables (e.g. saute [so:t] 'jump', seau [so] 'bucket'; jeûne [3ø:n] 'fast', jeu [3ø] 'game'). FÊTE simply cannot appear in open syllables; it is therefore always long and it always has the potential to be diphthongized. Second, for all vowels but FÊTE, quality is definitely seen as prevailing over length. For example, the phonological contrast between vowels like /a/ and /a/ in patte [pat] 'paw' and pâtes [pa:t] 'pasta' is attributed to a difference in backness, the longer duration of /a/ being treated as incidental. However, for Martin (1995), FÊTE is first and foremost longer than FAITE, which makes it the only vowel of Quebec French for which length has been posited as the dominant contrastive cue. Third, in syllables closed by a lengthening coda, FÊTE and FAITE should be neutralized, as FAITE theoretically has the potential to be diphthongized now that it is longer. As alluded to above, it is not always what happens with /v/ or / vb/ (Santerre 1981). In words like lève [le:v] 'rise' or chèvre [ $\left[\varepsilon_{\mathrm{V}} \mathrm{VG}\right]$ 'goat', the FAITE vowel is never diphthongized, despite being stressed and

\footnotetext{
${ }^{1}$ This corresponds to the most widely accepted (and simplest) lengthening rule, although some authors add nuances: Dumas (1981), for example, posits that vocalic lengthening is not categorical before $/ \mathrm{v} /$ and /3/, while Côté (2010) claims / $\mathbf{3} /$ is the only coda that systematically lengthens vowels.
} 
followed by a lengthening coda. When it comes to FAITE-FÊTE, a longer duration is thus necessary, but not sufficient, for diphthongization to happen. This is one of the facts that had initially led Santerre (1981) to suggest that underlying phonological representations were at play, unlike for other contextually diphthongized vowels.

If we now turn to acoustic descriptions of FAITE-FÊTE, one of the earliest is provided by Santerre (1974), who first notes that the duration of FÊTE is twice as long as that of FAITE. The first two formants always diverge over the course of the FÊTE vowel (F1 decreases and/or F2 increases), while they tend to converge over the course of FAITE. Drawing from his dissertation (Santerre 1971), in which articulatory and acoustic measurements were taken from two speakers of different socioeconomic backgrounds, Santerre (1974) also highlights that FÊTE is only diphthongized by the lower class speaker. Nonetheless, the higher class speaker produces FÊTE vowels that are acoustically distinct from FAITE: even when diphthongization is not perceived, FÊTE keeps its signature longer duration and diverging F1 and F2. Finally, Santerre (1974: 123) briefly alludes to a perception experiment where FÊTE was deliberately shortened and FAITE lengthened - listeners were never misled by these manipulations and always correctly identified the original vowel. For this author then, FÊTE is mainly characterized by its quality, not duration, and he transcribes it as $/ 3 /$. This choice of symbol seems purely arbitrary, since at no point does Santerre (1974) mention some sort of centralization, which would be expected if $/ 3 /$ had been drawn from the IPA vowel chart. A quick parenthesis should be made regarding the fact that, more recently, Côté (2012: 240-241) justifies using that same symbol given the central quality of the FÊTE vowel, with references to Santerre $(1974,1981)$. As mentioned above, Santerre himself does not allude to centralization in 1974 while in his 1981 phonological reflection, he claims that FÊTE has the same starting point as FAITE and is subsequently fronted ('articulation ... avançante' (Santerre 1981: 377)), which we do not think can be taken as evidence of centralization.

Martin (1995) also provides an acoustic description of the FAITE and FÊTE vowels produced by undergraduate students aged from 19 to 21 years. First, the author proceeds to an auditory categorization and comes up with the three following groups:

\section{A. short and monophthongal FAITE \\ B. long and diphthongal FÊTE \\ C. long and monophthongal FÊTE}

The few vowels belonging to group C likely correspond to those produced by Santerre's (1974) upper class speaker, but all in all, Martin (1995) considers that in the 1990s, diphthongization of FÊTE has become the norm among young university students. In terms of duration, FAITE vowels can be half as long as FÊTE vowels (groups B and C), a tendency also observed by Santerre (1974). The acoustic distance between F1 and F2 slightly shrinks over the course of FAITE and group C FÊTE, whereas for group B FÊTE, F1 and F2 grow farther apart. These results are slightly different from Santerre's (1974), whose group C FÊTE vowels showed formant trajectories similar to group B. Furthermore, Martin (1995: 44) highlights the 'compact' onset of diphthongal FÊTE vowels, that is, high F1 and relatively low F2. The diphthong would thus start as [a] and further rise and front. Martin (1995) nonetheless maintains / $\varepsilon$ :/ for his phonological transcriptions, thereby implying that a longer duration is the dominant characteristic of FÊTE.

Let us now say a few words about a recent study by Leblanc (2012), whose main goal is to identify the acoustic properties of diphthongal vowels in Quebec French. Three trained phoneticians first transcribed 2760 naturally uttered words - only those that contained vowels that the majority perceived as diphthongal were kept for further analyses, that is, $17.7 \%$ of the initial corpus. Leblanc (2012) reports that the FÊTE vowel is by far the most frequently uttered diphthongal, at $92 \%$. The author also shows, with Bark transformed F1-F0 and F2-F1 distances, that the onset of FÊTE shares properties with /a/, after which rising and fronting towards / $/ \varepsilon /$ and /e/ occur. 
Even more recently, Côté \& Lancien (2019) used recordings from the PFC project (Phonologie du français contemporain; Durand, Laks \& Lyche 2009) to follow up on Santerre's (1974) work. In addition to the usual FAITE and FÊTE, they analyze words morphologically derived from FÊTE, in which the vowel of interest is not stressed (fêtard, fêter, fêteriez). The authors find that the length distinction between FAITE and FÊTE is only maintained under stress. In an F1/F2 plane, FÊTE rises and fronts, although the trajectory of the stressed vowel is greater than that of the unstressed vowels, while FAITE follows the opposite trajectory (reduced lowering and backing). Finally, the authors set up a lexical decision task where 44 listeners categorized (stressed) FÊTE and FAITE tokens that naturally varied in length. The results suggest that relatively short FÊTE and long FAITE were rarely misidentified by the participants. This led Côté \& Lancien (2019) to conclude that the FAITE-FÊTE distinction is driven by vowel quality.

To sum up, Santerre (1974) underscores the divergent trajectory of the first two formants of FÊTE, in addition to the obviously long duration of the diphthong. Contrastively, Martin (1995) focuses on the compact onset of the vowel. Leblanc's (2012) data clearly shows a vowel that rises and fronts from the /a/ area, which is corroborated by Côté \& Lancien's (2019) analysis, as well as Santerre's (1981) and Martin's (1995) comments. Occasionally, FÊTE is long but monophthongal. In such cases, Santerre (1974) considers it to share the acoustic properties of diphthongal FÊTE, though Martin (1995) finds it is more similar to monophthongal FAITE, a discrepancy that partly explains why the former uses $/ 3 / \mathrm{l}$ and the latter / $\varepsilon$ : in their transcriptions. Leblanc (2012) exclusively focuses on diphthongal vowels in the acoustic part of his study, but his descriptive statistics show that instances of monophthongal FÊTE are marginal $(8 \%)$ in the 2010 s, a tendency that also arises from Martin's (1995) classification. We will elaborate on this further below with our own empirically based acoustic description of FÊTE.

\section{Methods}

\subsection{Speech material}

In order to best describe FÊTE, we chose to compare it with FAITE, along with the entire vocalic system of Quebec French. Note that this strategy is intended to locate FÊTE in the acoustic space and highlight its characteristics, and not to exhaustively describe Quebec French (we refer those interested in a more complete description to Martin 1996, Paradis \& Dolbec 1998, Côté 2012). On account of the technical difficulties involved in the acoustic analysis of nasal vowels, our study focuses exclusively on oral vowels.

We set up reading tasks that would bring speakers to utter all Quebec French oral vowels in stressed syllables, specifically: [i I y y u u e $\varnothing$ o $œ ~ \supset$ a a], FAITE and FÊTE. The only historically long vowels taken into consideration are thus /ø o d/ and FÊTE. Note that schwa is not included in the list as it is usually not stressed. It is also worth mentioning that in Quebec French, the high vowels /i y u/ split into mutually exclusive 'tense' and 'lax' variants, respectively [i y u] and [ I Y U], the latter appearing in stressed syllables closed by a non-lengthening coda, and the former elsewhere. Moreover, we chose to avoid lengthening codas, since these can significantly modify vowel duration and the potential for contextual diphthongization, as well as partly neutralize the distinction between FAITE and FÊTE (see Section 2). The 15 aforementioned vowels were thus produced in syllables closed by a non-lengthening coda or in open syllables, for a total of 57 different lexical items, as shown in Appendix A.

Each of these 57 lexical items was produced over the course of three reading tasks (every lexical item uttered three times). Task 1 consisted of participants reading out of context, but meaningful, carrier sentences ending with a target lexical item. For example, the following 
sentences featured the target words bete 'grumpy' (FÊTE vowel) and belle 'beautiful' (FAITE vowel):

- Le matin, j'ai l'air bête.

'In the morning, I am (or look) grumpy.'

- La vie est belle.

'Life is beautiful.'

Task 2 featured the same target words within a fixed carrier sentence. Appearing at the end of an accentual phrase, they were stressed:

- Je pense au mot bête très fort.

'I am thinking very hard about the word "grumpy".'

- Je pense au mot belle très fort.

'I am thinking very hard about the word "beautiful".'

Task 3 again featured the 57 target lexical items, but this time in isolation:

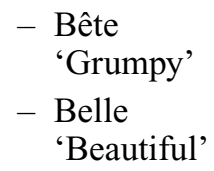

The main reason for designing three different tasks was to avoid a task effect. Additionally, each task had its own strengths and weaknesses. Task 1 avoided all possible lexical confusion, but frequently gave way to phenomena like breathy and creaky voice. This was avoided in Task 2, but coarticulation effects might have been more prevalent. Task 3 may have provoked unnatural prosodic patterns, but isolated words could be easily reused in other studies, for example perception experiments. We are aware that slight cross-task variation may arise, but the relative characteristics of the vowels remain unchanged. As explained in Section 3.3, this has been taken into account in our statistical analyses.

The words presented to the speakers over the three reading tasks correspond to a standard but common register in Quebec French and comprise some dialectal particularities (e.g. gougoune 'plastic sandal/thong'). Lexical frequency was not explicitly controlled for. The participants were instructed to read, in an as natural a manner as possible, the sentences or words appearing individually on the screen of an electronic tablet at a rate controlled by the experimenter. A short training phase helped them familiarize themselves with the three tasks. They were recorded individually in a sound-attenuated booth, using a Zoom H4n (digital format, 44,100 Hz, 16 bits).

\subsection{Speakers}

Fifty-four participants were recruited for this study; all were undergraduate students enrolled at Université Laval in September 2016. Data from two speakers were excluded as their parents were from France, they had lived abroad for several years and their pronunciation comprised features of European French, such as three nasal vowels instead of four and tense variants of $/ \mathrm{i} \mathrm{y} \mathrm{u} /$ in syllables closed by a non-lengthening coda. The remaining 52 participants, 37 women and 15 men aged from 18 to 23 years, were native speakers of Quebec French. Twenty were born and raised in Quebec City or Levis (a city on the south shore of the St. Lawrence River across from Quebec City), while the others came from various towns and cities across the province and had just moved to Quebec City to start university. None of them had lived outside the province of Quebec, except for short intervals (e.g. a six-month student exchange in South America to learn Spanish or a summer spent in British Columbia). They were compensated $\$ 10$ for their time. 


\subsection{Analysis}

The recorded speech was analyzed acoustically using Praat (Boersma \& Weenink 2019). The 8892 tokens ( 57 words $\times 3$ tasks $\times 52$ speakers) were first segmented manually by a trained acoustician, who identified vocalic boundaries based on at least one of the following cues: periodicity, intensity, formant structure, voice bars, high-frequency noise, bursts, etc. Twenty-six tokens were discarded when segmentation or further analysis was deemed impossible, leaving 8866. Duration was measured, as well as frequency of the first two formants at three time points: at $25 \%, 50 \%$ and $75 \%$ of the vowel duration. This part of the analysis was also performed manually, with the formant detection ceiling and number of formants to be detected in the frequency interval optimized for each speaker and each vocalic category when needed, they were adjusted per token.

Taking into account more than one formant measurement set was motivated by the fact that we are dealing with diphthongal vowels, which typically have a complex vocalic core and formants that do not truly stabilize (Lehiste \& Peterson 1961). Our choice of measuring formants near the onset (25\%) and offset $(75 \%)$ of the vowel is inspired by the 'dual target' parameterization proposed in the literature focusing on spectral changes (Nearey \& Assmann 1986, Morrison \& Assmann 2013). However, we used them to compute a single metric that accounts for the temporal evolution of a given formant $\left(\mathrm{F}_{\mathrm{x}}\right)$, as follows:

$$
-\mathrm{F}_{\mathrm{x}} \text { dynamics }=\mathrm{F}_{\mathrm{x}} \text { at } 75 \%-\mathrm{F}_{\mathrm{x}} \text { at } 25 \%
$$

Here is a concrete example. If the $\mathrm{F} 1$ of a given vowel has a frequency of $500 \mathrm{~Hz}$ at $25 \%$, its dynamics will be of $10 \mathrm{~Hz}$ if its frequency rises to $510 \mathrm{~Hz}$ at $75 \%$, while its dynamics will be of $-10 \mathrm{~Hz}$ if its frequency lowers to $490 \mathrm{~Hz}$ at $75 \%$. A negative value thus indicates that $\mathrm{F}_{\mathrm{x}}$ has had its frequency lowered over the course of the vowel, while the opposite is true for a positive value. We computed the formant dynamics for every vowel, not exclusively for FÊTE, in order to highlight its specific properties.

Linear mixed effects models were fit to the data using the lme4 package (Bates et al. 2015 ) in the $\mathrm{R}$ environment ( $\mathrm{R}$ Core Team 2019). Duration and the dynamics of $\mathrm{F} 1$ and F2 were set as response variables in separate models. Initially, random effects included the speakers, as well as the words nested within the tasks. A factor combining the vowel and type of syllable it was produced in (open or closed) was created and set as fixed effect, in addition to the speakers' sex and their interaction. The step() function of the lmerTest package (Kuznetsova, Brockhoff \& Christensen 2017) then made it possible to eliminate non-significant interactions or factors. We visually assessed whether variance was homogeneous and residuals normally distributed. As duration presented a heteroscedasticity problem, the model was rerun on log-transformed duration. Post-hoc pairwise comparisons were conducted using the emmeans package (Lenth, Love \& Herve 2018), with degrees of freedom calculated with the Satterthwaite equation and adjusted $p$-values with the Tukey method. The significance level has been set to 5\%. Model summaries are displayed in Appendix B.

\section{Results}

In this section, we first present results on duration, followed by those on formant frequencies. Duration is presented with the help of boxplots, hence the data is not averaged. On the contrary, formant frequencies have been averaged, first per speaker, then across speakers. The data has not been normalized. Where appropriate, the results have been split per syllable type (open or closed, henceforth OS and CS), as this can lead to substantial differences, especially in duration. This is also how the statistical analyses were performed. The results of the three tasks are presented jointly. Note that in the graphs displayed hereafter, FÊTE is symbolized by ' $\hat{\varepsilon}$ ' and FAITE by ' $\varepsilon$ '. 


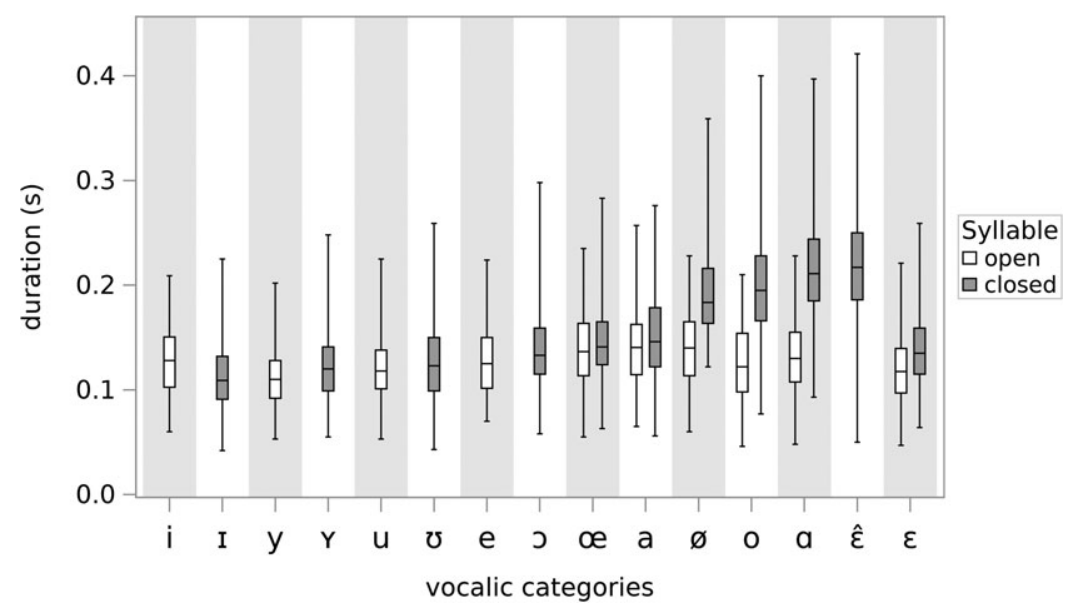

Figure 1 Duration of 15 vocalic categories (52 speakers, 8866 vowels), per type of syllable (open or closed). Whiskers comprise extreme values.

Figure 1 suggests that FÊTE has the longest duration of all, but also the widest distribution, as shown by its spread whiskers. The vowels /a o ø/ have comparably long durations when produced in CS. This is coherent with historical length only emerging in CS, as explained in Section 2. The short variants of /a o ø/ produced in OS have durations comparable to those of the intrinsically short vowels, the durations of which do not seem much influenced by the type of syllable they were produced in.

If we observe the duration ratio between FAITE and FÊTE, we find it to be somewhat smaller than that reported by Santerre (1974) and Martin (1995), who both observe that FÊTE is twice as long as FAITE. In our own data, the mean duration of FAITE $(0.136 \mathrm{~s}$ across syllable types) represents two thirds of the duration of FÊTE $(0.220 \mathrm{~s})$. Nonetheless, FÊTE is statistically significantly different from FAITE in both OS and CS (OS: $\beta=-0.532$, s.e. $=0.104$, $t(1.41)=-5.101, p<.001 ; \mathrm{CS}: \beta=-0.282$, s.e. $=0.031, t(2.41)=-8.909, p<.001)$. However, the estimated duration of FÊTE does not differ from that of /a o $\varnothing /$ in $C S(/ a /: \beta=0.066$, s.e. $=0.059, t(1.68)=1.108, p=.2692 ; / \mathrm{o} /: \beta=0.006$, s.e. $=0.052, t(2.08)=0.115$, $p=.9082 ; / \varnothing /: \beta=-0.063$, s.e. $=0.074, t(2.67)=-0.852, p=.3952)$, while it does from all the rest (see Table B2 of Appendix B for more details).

Figure 2 illustrates how formant frequencies evolve from $25 \%$ to $75 \%$ of the vowel duration. We observe that only /a/ and /a/ in OS, respectively located in the first (Q1) and second (Q2) quadrants, see their first formant rise over time. For the other vowels, F1 drops to various degrees or stays roughly the same. Vowels in Q2 and Q3 have their second formant lowered, while F2 rises in Q1 and Q4 vowels. Except for /i/, male and female productions are located in the same quadrants. However, some of the vowels produced by the male speakers have slightly reduced trajectories compared to those produced by the female speakers, for example /y/, /œ/ in OS (which overlaps with /œ/ in CS) or FÊTE. This is likely due to the fact that male formant frequencies are usually lower, and that smaller differences in low frequencies have similar perceptual consequences as larger differences in higher frequencies. While certain vowels produced in both types of syllables are located in the same quadrant, for example $/ \mathrm{o} /$ and $/ \varnothing /$, it is not always the case. In addition to $/ \mathrm{a} /$ and $/ \mathrm{a} /$ that were already mentioned, FAITE is located in Q3 when in CS and Q4 in OS. There is no clear tendency for front and back vowels to follow a particular direction: their second formant may as well rise or drop. 

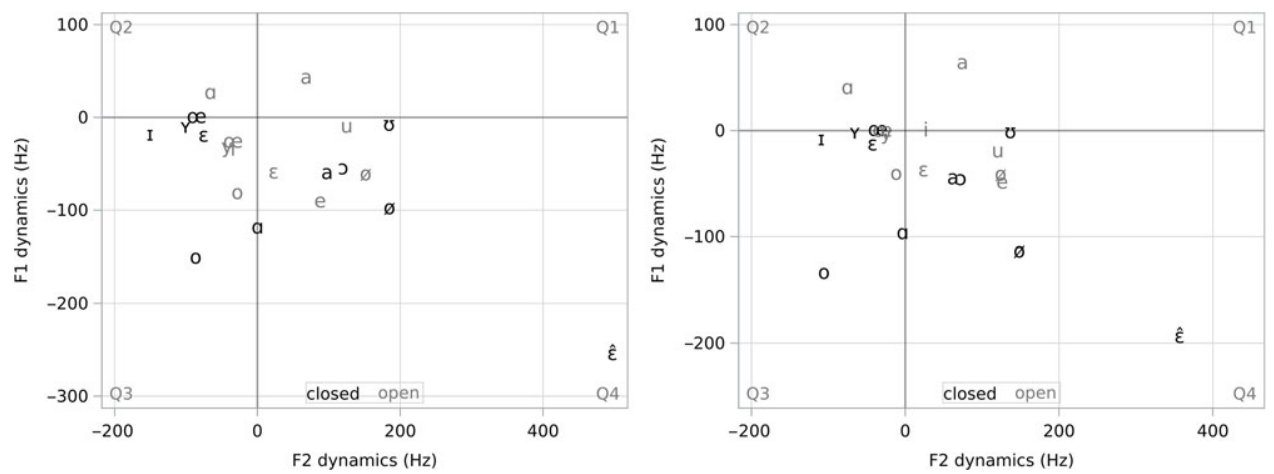

Figure 2 Mean formant dynamics from 25\% to 75\% of vowel duration (8866 vowels, 37 female speakers on the left, 15 male speakers on the right). A negative value in one of the four quadrants (Q1-Q4) corresponds to a decreasing formant frequency over the course of a vowel.

Perhaps the most striking observation emerging from Figure 2 is the location of FÊTE in Q4, far from the other vowels. Both F1 and F2 undergo extensive change over the course of FÊTE, including a considerable mean rise of $497 \mathrm{~Hz}$ on F2 in female speakers and $357 \mathrm{~Hz}$ in male speakers. If anything, this suggests that if only one vowel has been diphthongized, it has to be FÊTE. Qualitatively, these findings confirm those of Santerre (1974) and Martin (1995), in that the first two formants of FÊTE diverge over time (F1 drops while F2 rises). Côté \& Lancien (2019) report the opposite trajectory for FAITE (F1 rising and F2 dropping), a trend that is only partly confirmed here. In CS, the F2 of FAITE does drop, while its F1 does not rise; in OS (not analyzed by Côté \& Lancien 2019), the formants of FAITE follow the same trajectory as FÊTE, although less markedly. Statistically speaking, the estimated F1 and F2 dynamics for FÊTE are significantly different from those of all the other vowels for female speakers (see Appendix B). For male speakers, FÊTE and $/ \varnothing /$ in CS do not exhibit significantly different $\mathrm{F} 1$ dynamics $(\beta=-73.62$, s.e. $=26.34, t(452)=-2.795, p=.7148)$. Also for male speakers, the difference between the F2 dynamics of FÊTE and that of /e/, /u/ and $/ \varnothing /$ in both types of syllables only shows a trend towards significance $(/ \mathrm{e} /: \beta=269.98$, s.e. $=71.9, t(184)=3.758, p=.0992 ; / \mathrm{u} /: \beta=277.38$, s.e. $=71.9, t(185)=3.857, p=.0736$; $/ \varnothing / \mathrm{CS}: \beta=218.08$, s.e. $=56, t(405)=3.893, p=.0589 ; / \varnothing /$ OS: $\beta=272.09$, s.e. $=71.9$, $t(184)=3.787, p=.0910)$. This might be due to the relatively low number of male speakers in our study (only 15), or to a tendency for either female speakers to diphthongize FÊTE particularly strongly, or male speakers to produce vowels other than FÊTE with substantial spectral changes.

Figure 3 presents a more familiar illustration of the mean formant frequencies for the vowels across syllable types. The vowel spaces represented offer no surprise, although two characteristics are worth mentioning. One is the location of /e/, very close to /i/, whereas the other mid-close vowels, /ø/ and /o/, are well distinguished from the high vowels on the F1 axis. It is probable that the third and fourth formants, not represented here, contribute to further distinguishing /i/ and /e/ acoustically, the former reputedly having high frequency focalized F3 and F4 (Ménard 2002). The second characteristic is the location of $/ 0 /$ along the F2 axis. This tendency for $/ \mathrm{s} /$ to centralize, well documented in European French since Martinet (1958), has also been attested in some studies on Quebec French (e.g. Martin 2002, St-Gelais 2019). Finally, the female and male vowel spaces displayed in Figure 3 are visually

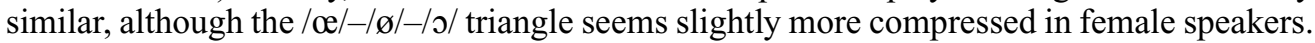

Now let us consider FÊTE. If we first concentrate on values at $50 \%$ duration (illustrated by the small squares in Figure 3), we observe that when the vowel reaches its midpoint, 

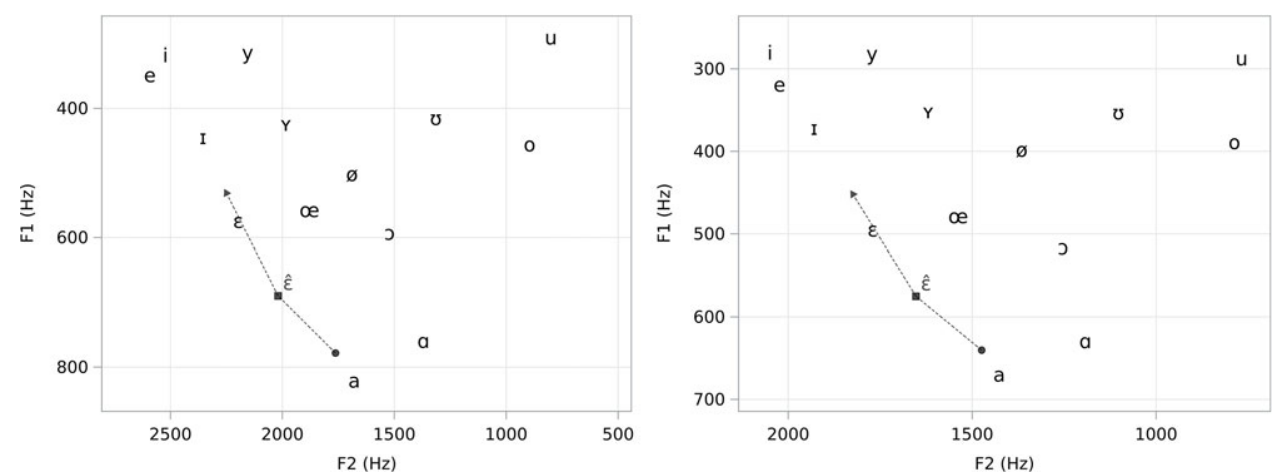

Figure 3 F1/F2 planes showing relative mean position and dynamics of FÊTE as produced by 37 female speakers on the left and 15 male speakers on the right. Circles show FÊTE at 25\% duration, squares at 50\% and triangles at 75\%. All the other vowels are at 50\%.

it is approximately halfway between /a/ and FAITE in the F1/F2 planes, in a position that roughly corresponds to $/ \mathfrak{m} /$ in the IPA vowel chart. However, the most interesting part is the trajectory of FÊTE. At $25 \%$ duration, its first two formants present values similar to those of $/ \mathrm{a} /$, while they reach the FAITE area at $75 \%$ duration. Some fronting and extensive rising thus characterize the temporal evolution of FÊTE, which is consistent with Leblanc's (2012) data and Martin's (1995) remark. We are less inclined, however, to acknowledge the latter's claim that the compact onset of FÊTE is a key feature. With average values of $778 \mathrm{~Hz} \times 1760 \mathrm{~Hz}$ for female speakers and $640 \mathrm{~Hz} \times 1474 \mathrm{~Hz}$ for male speakers, the first two formants of FÊTE are not especially close, notably when compared to, say, /o/ $(456 \mathrm{~Hz} \times 895 \mathrm{~Hz}$ for females, $389 \mathrm{~Hz} \times 787 \mathrm{~Hz}$ for males). Neither do our results support Santerre's (1981) comment about FÊTE and FAITE starting alike and then differing. In fact, the limited trajectory of FAITE evidenced in Figure 2 makes it very unlikely it starts as low as FÊTE. While both vowels may well END similarly, they have radically different starting points.

In conclusion, our results show that FÊTE has the longest duration among the vocalic categories analyzed, although it is closely followed by the other historically long oral vowels /ø o a/ in CS (Figure 1), from which it does not differ statistically. FÊTE is clearly distinct when we observe formant trajectories over time. F1 and F2 change considerably: they start with values similar to those of $/ \mathrm{a} /$ at $25 \%$, reach the $/ \mathfrak{x} /$ area at $50 \%$ and FAITE at $75 \%$ of the duration of FÊTE (Figure 3). The magnitude of this temporal evolution is matched in no other vowel produced by the female speakers, and in very few vowels produced by the male speakers (Figure 2).

\section{Discussion and conclusion}

In this article, we have sought to describe the Quebec French vowel FÊTE. In this variety of French, a stressed long vowel is frequently diphthongized, no matter if its length is a consequence of the following coda or an intrinsic property of the vowel itself. FÊTE, however, has retained the attention of numerous authors over the years due to its unparalleled acoustic characteristics and a particularly strong tendency to be produced with a complex nucleus. Regardless, its status has so far remained imprecise, especially regarding its dominant distinguishing feature and the way it should be transcribed. Our main goals were thus to determine whether length or quality made FÊTE stand out and propose a phonetic transcription that would fit both recently gathered empirical data and the International Phonetic Alphabet. 
To do so, we have acoustically analyzed 8866 vowels produced by 52 native speakers of Quebec French aged from 18 to 23 years. Our results first show that FÊTE has one of the longest durations of the vocalic categories analyzed, but that it is not statistically different from the other historically long vowels considered, /a o ø/ in CS. At 50\% duration, the first two formants of FÊTE have values that locate it halfway between /a/ and FAITE in F1/F2 planes. Taking into account more than one formant measurement set reveals tremendous spectral changes in FÊTE. Near the onset, it is similar to /a/, whereas it finishes near FAITE, indicating that the location captured at $50 \%$ duration is just an intermediate step in its long fronting and rising trajectory. The vowels /a o ø/ in CS, despite being as long as FÊTE, do not show such extensive dynamics.

In light of these findings, what can we conclude about the dominant cue of FÊTE? Note that Santerre (1974) and Côté \& Lancien (2019) put forward quality rather than length. In the first study, this view was justified by the divergent F1 and F2 trajectories of FÊTE, while the latter pointed to length reduction in unstressed FÊTE, a trajectory opposite to FAITE in the vocalic space and right identification of short FÊTE by listeners. Contrastively, Martin (1995) comes to the conclusion that FÊTE is first and foremost longer. In a way, they are all right: if we only focus on the FAITE-FÊTE distinction, we might as well consider length or quality to be the most distinguishing feature. This is where looking at the whole vocalic system of Quebec French, like we have done in the current study, brings crucial depth. If FÊTE is undoubtedly longer than FAITE, its duration is very similar to that of / $\mathbf{a} \varnothing \mathrm{o} /$, while none of these intrinsically long vowels presents as substantial formant dynamics. We argue that what truly characterizes FÊTE and makes it different from the other vowels of Quebec French is its quality, more precisely its DIPHTHONGAL quality.

We will now meet our objective of proposing a transcription of FÊTE that we consider appropriate. Let us recall that Santerre $(1974,1981)$ suggests using /3/. However, none of the uncovered acoustic properties of FÊTE matches what this symbol represents in the IPA. We understand from Santerre's papers that, originally, /3/ was not meant to reflect some sort of central quality. Since it has come to be used in that way in recent years (see Côté 2012), we think $/ 3 /$ is ambiguous and should be dismissed.

Martin (1995) uses / $\varepsilon: /$. The duration of FÊTE is indeed long, but it is no different from the other historically long vowels. Moreover, given that $/ \varepsilon /$ is used to represent FAITE, / $\varepsilon$ : would mean that FÊTE is just a longer FAITE. Now, what we think distinguishes FÊTE is the trajectory of its first two formants. F1 and F2 shift considerably more over the course of FÊTE than of the other vowels, including FAITE, and as suggested in Figure 3, span two vocalic qualities of Quebec French. Since we argue that this characterizes the FÊTE vowel, it should be reflected more in its transcription than duration; therefore, we also put $/ \varepsilon$ :/ aside. Given the evidence we have just given, we conclude that an appropriate symbol for FÊTE would be /aع/. This is, of course, a phonemic transcription, while the phonetic realizations may differ and be transcribed otherwise, for example [aI] or [ae].

On another matter, we wish to call the attention on the fact that the studies summarized in Section 2 cover four decades of spoken Quebec French. One of the things that seem to have evolved is the in-between category of long but monophthongal FÊTE (group C). While such realizations make for a large part of Santerre's (1974) description, notably in his arguing that however it is produced, FÊTE has a distinctive acoustic signature, Martin (1995) has to deal with this to a lesser extent. In Leblanc's (2012) study, a very large majority (92\%) of the expected FÊTE tokens were diphthongal, but the author simply discarded the remaining $8 \%$ without describing them further. We cannot conclude, then, that they are residual instances of long but monophthongal FÊTE; they might as well have been short and similar to FAITE. As for our own data, the following remark may seem anecdotal, but it is nonetheless of importance for this discussion. The first author, who analyzed the data and is a native speaker of Quebec French, is under the impression that the participants did not produce long but 
monophthongal FÊTE vowels. Diphthongization was occasionally less prominent, but never to the point that an intermediate category like Martin's (1995) group C was needed. Tokens were either long and diphthongal, or short and monophthongal. Some inter-speaker variation did occur for certain words (e.g. plaide 'plead'), but it was always clear whether the vowel produced was FAITE- or FÊTE-like. It is thus a possibility that FAITE and FÊTE have become increasingly distinct over the years. If it were the case that such a change has happened, our results would suggest that it is led by female speakers, for whom the acoustic dissimilarity between FÊTE and the other categories analyzed is statistically and visually significant and greater than for male speakers (Figure 2). One question that remains open is whether FÊTE is still subject to social conditioning as it used to be in Santerre's (1971) days (see also YaegerDror \& Kemp 1992). Words like baleine 'whale' and arrête 'stop' tend to act as shibboleths

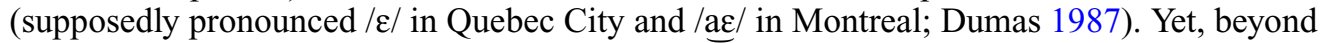
the odd stereotypical lexical items, how conscious are listeners of diphthongal FÊTE and how do they judge it?

Our study has limitations that must be mentioned. First, we have analyzed read speech produced by 52 speakers aged from 18 to 23 years. It does not reflect all possible Quebec French usages. Moreover, our conclusions are based on a handful of acoustic parameters. Given the complexity of speech, however, it could have been described in a much richer way, including in terms of spectral changes. Also, we have used a limited lexical set that was identical across speakers, but not otherwise controlled. Additionally, our participants were from various cities across the province and were equally considered 'Quebec French speakers', but we do not discount the possibility of regional variation being present in the data. Beyond baleine and arrête, Dolbec \& Ouellon (1999) point out that speakers from Western Quebec (Montreal and the surrounding area) reputedly diphthongize vowels more strongly than speakers from Eastern Quebec (Quebec City and the surrounding area), which might be worth further investigation in future studies about diphthongal FÊTE. ${ }^{2}$

Finally, we are conscious that we have offered a very incomplete picture of diphthongization of Quebec French vowels by choosing to exclude lengthening codas. Future work will address this issue in due form, more specifically through a comparison of the acoustic profile of / $\mathrm{a} \varepsilon /$ and short vowels in lengthening codas. Given our findings with regard to /a $0 \varnothing /$, it is not unlikely /aع/ will remain acoustically distinct. After decades of researchers highlighting the specific nature of /a $/$ /, we felt it was high time this vowel had its own representative symbol, and in that regard, we have achieved the goals we set for ourselves in this study.

\section{Acknowledgments}

We wish to thank the editor and three anonymous reviewers for their useful suggestions. This work has been funded by the Social Sciences and Humanities Research Council of Canada (SSHRC).

\footnotetext{
$\overline{2}$ Côté \& Lancien (2019: 1533), whose main results were summarized in Section 2, make such an attempt to distinguish Eastern from Western productions of FÊTE, but severely lack clarity when concluding that Eastern Quebec French speakers 'display diphthongs that are more anterior.' First, this comment is based on averaged values that may not reveal fronting MOVEMENT. Second, since the authors' statistical analyses uncover significant differences on F1, we do not understand why they only insist on fronting. It should be noted that F1 and F2 tend to vary concomitantly in front vowels due to articulatory constraints. Lastly, the authors suggest that 'anterior diphthongs' as a distinguishing feature between Eastern and Western speakers had already been mentioned by Dolbec \& Ouellon (1999), though any mention of this could not be found after a careful review of that paper. On another matter, Côté \& Lancien (2019: 1530) write that Santerre $(1974,1981)$ 'adopts the symbol /3:/for the long vowel', which, once more, we could not find in the original papers: the author uses $/ 3 /$, without the length mark.
} 


\section{Appendix A. Target lexical items}

Table A1 The 57 target lexical items produced by the participants and analyzed in the current study, grouped per vocalic category. The type of syllable these items represent is in parentheses, where OS stands for open syllable and CS, for closed syllable.

\begin{tabular}{|c|c|c|}
\hline [i] & {$[\mathrm{y}]$} & {$[\mathrm{u}]$} \\
\hline vie 'life' (OS) & déchu 'deposed' (OS) & fou 'crazy' (OS) \\
\hline [I] & {$[\mathrm{Y}]$} & {$[\mathrm{U}]$} \\
\hline $\begin{array}{l}\text { frite 'French fry' (CS) } \\
\text { figue 'fig' (CS) } \\
\text { pile 'battery' (CS) } \\
\text { friche 'fallow' (CS) } \\
\text { frime 'bluff' (CS) }\end{array}$ & $\begin{array}{l}\text { flûte 'flute' (CS) } \\
\text { élude 'avoid' (CS) } \\
\text { cellule 'cell' (CS) } \\
\text { puce 'flea' (CS) } \\
\text { lune 'moon' (CS) }\end{array}$ & $\begin{array}{l}\text { soupe 'soup' (CS) } \\
\text { soude 'weld' (CS) } \\
\text { houle 'swell' (CS) } \\
\text { débouche 'lead to' (CS) } \\
\text { gougoune 'thong' (CS) }\end{array}$ \\
\hline$[\mathrm{e}]$ & {$[\varnothing]$} & [œ] \\
\hline aller 'to go' (OS) & $\begin{array}{l}\text { veu 'wish' (OS) } \\
\text { jeûne 'fast (noun)' (CS) }\end{array}$ & $\begin{array}{l}\text { le 'it' (OS) } \\
\text { veulent 'want' (CS) } \\
\text { cuuf 'egg' (CS) } \\
\text { jeune 'young' (CS) }\end{array}$ \\
\hline [o] & [0] & {$[\mathrm{a}]$} \\
\hline $\begin{array}{l}\text { peau 'skin' (OS) } \\
\text { rauque 'hoarse' (CS) } \\
\text { aube 'dawn' (CS) } \\
\text { drôle 'funny' (CS) } \\
\text { fosse 'pit' (CS) } \\
\text { jaune 'yellow' (CS) } \\
\end{array}$ & $\begin{array}{l}\text { bloc 'block' (CS) } \\
\text { blogue 'blog' (CS) } \\
\text { école 'school' (CS) } \\
\text { bosse 'bump' (CS) } \\
\text { pomme 'apple' (CS) }\end{array}$ & $\begin{array}{l}\text { état 'state' (OS) } \\
\text { Pâques 'Easter' (CS) } \\
\text { châle 'shawl' (CS) } \\
\text { lâche 'release' (CS) } \\
\text { âne 'donkey' (CS) }\end{array}$ \\
\hline [a] & FAITE & FÊTE \\
\hline $\begin{array}{l}\text { fa 'F (music note)' (OS) } \\
\text { flaque 'puddle' (CS) } \\
\text { blague 'joke' (CS) } \\
\text { pédale 'pedal' (CS) } \\
\text { face 'face' (CS) } \\
\text { femme 'woman' (CS) }\end{array}$ & $\begin{array}{l}\text { passait 'passed by' (OS) } \\
\text { bec 'beak' (CS) } \\
\text { plaide 'plead' (CS) } \\
\text { belle 'beautiful' (CS) } \\
\text { crèche 'manger' (CS) } \\
\text { sème 'sow' (CS) }\end{array}$ & $\begin{array}{l}\text { bête 'grumpy' (CS) } \\
\text { aide 'help' (CS) } \\
\text { caisse 'crate' (CS) } \\
\text { mêle 'confuse' (CS) }\end{array}$ \\
\hline
\end{tabular}




\section{Appendix B. Summaries of the linear mixed effects models}

Table B1 Model summary for duration.

\begin{tabular}{|c|c|c|c|c|c|c|c|}
\hline & & Estimate & Sth. error & d.f. & t-value & $\operatorname{pr}(>|t|)$ & Sig. \\
\hline Intercept & & $-1.637 \mathrm{e}+00$ & $3.999 e-02$ & $2.427 \mathrm{e}+02$ & -40.932 & $<2 e-16$ & $* * *$ \\
\hline VowSyl & ø, closed & $-6.335 \mathrm{e}-02$ & $7.440 e-02$ & $2.670 \mathrm{e}+02$ & -0.852 & 0.395243 & \\
\hline VowSyl & ø, open & $-3.580 e-01$ & $1.045 e-01$ & $1.419 e+02$ & -3.428 & 0.000797 & $* * *$ \\
\hline VowSyl & $\mathbf{a}$, closed & 6.644e-02 & $5.994 \mathrm{e}-02$ & $1.686 \mathrm{e}+02$ & 1.108 & 0.269232 & \\
\hline VowSyl & $\mathbf{a}$, open & $-4.461 e-01$ & $1.045 e-01$ & $1.419 \mathrm{e}+02$ & -4.271 & $3.55 e-05$ & $* * *$ \\
\hline VowSyl & o, closed & 6.044e-03 & $5.237 e-02$ & $2.087 \mathrm{e}+02$ & 0.115 & 0.908233 & \\
\hline VowSyl & o, open & $-3.297 \mathrm{e}-01$ & $9.385 e-02$ & $2.156 \mathrm{e}+02$ & -3.513 & 0.000539 & $* * *$ \\
\hline VowSyl & œ, closed & $-2.977 \mathrm{e}-01$ & $6.280 \mathrm{e}-02$ & $1.674 e+02$ & -4.735 & $4.65 e-06$ & $* * *$ \\
\hline VowSyl & œ, open & $-3.822 \mathrm{e}-01$ & $1.045 e-01$ & $1.419 e+02$ & -3.659 & 0.000356 & $* * *$ \\
\hline VowSyl & a, closed & $-2.830 e-01$ & $5.625 e-02$ & $1.678 \mathrm{e}+02$ & -5.030 & $1.25 e-06$ & $* * *$ \\
\hline VowSyl & a, open & $-3.617 \mathrm{e}-01$ & $1.045 e-01$ & $1.419 e+02$ & -3.463 & 0.000707 & $* * *$ \\
\hline VowSyl & $\varepsilon$, closed & $-2.820 \mathrm{e}-01$ & $3.165 e-02$ & $2.417 \mathrm{e}+03$ & -8.909 & $<2 \mathrm{e}-16$ & $* * *$ \\
\hline VowSyl & $\varepsilon$, open & $-5.328 \mathrm{e}-01$ & $1.045 e-01$ & $1.419 e+02$ & -5.101 & $1.06 \mathrm{e}-06$ & $* * *$ \\
\hline VowSyl & I, closed & $-5.161 e-01$ & $5.507 e-02$ & $1.711 e+02$ & -9.371 & $<2 e-16$ & $* * *$ \\
\hline VowSyl & i, open & $-7.601 \mathrm{e}-01$ & $7.917 \mathrm{e}-02$ & $3.260 \mathrm{e}+02$ & -9.600 & $<2 e-16$ & $* * *$ \\
\hline VowSyl & Y, closed & $-4.851 \mathrm{e}-01$ & $5.628 \mathrm{e}-02$ & $1.682 \mathrm{e}+02$ & -8.620 & $4.74 e-15$ & $* * *$ \\
\hline VowSyl & $\mathrm{y}$, open & $-6.063 e-01$ & $1.045 e-01$ & $1.420 \mathrm{e}+02$ & -5.804 & $4.06 \mathrm{e}-08$ & *** \\
\hline VowSyl & U, closed & $-4.732 \mathrm{e}-01$ & $5.545 e-02$ & $1.789 e+02$ & -8.533 & $5.94 e-15$ & $* * *$ \\
\hline VowSyl & $\mathrm{u}$, open & $-5.119 e-01$ & $1.045 e-01$ & $1.421 e+02$ & -4.899 & $2.59 e-06$ & $* * *$ \\
\hline VowSyl & $\mathrm{o}$, closed & $-4.190 e-01$ & $5.352 \mathrm{e}-02$ & $1.957 \mathrm{e}+02$ & -7.830 & $3.02 e-13$ & $* * *$ \\
\hline VowSyl & e, open & $-4.486 e-01$ & $1.045 \mathrm{e}-01$ & $1.419 \mathrm{e}+02$ & -4.295 & $3.23 e-05$ & *** \\
\hline
\end{tabular}

VowSyl = vowel, type of syllable

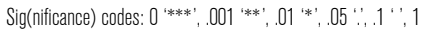

$\log ($ duration $) \sim$ VowSyl $+(1 \mid$ Speaker $)+(1 \mid$ Task:Word $)$ 
Table B2 Model summary for F1 dynamics.

\begin{tabular}{|c|c|c|c|c|c|c|c|}
\hline & & Estimate & Std. error & d.f. & $t$-value & $\operatorname{pr}(>|t|)$ & Sig. \\
\hline Intercept & & -257.419 & 11.193 & 269.766 & -22.998 & $<2 \mathrm{e}-16$ & $* * *$ \\
\hline VowSyl & $\varnothing$, closed & 147.477 & 23.621 & 304.902 & 6.244 & $1.43 e-09$ & $* * *$ \\
\hline VowSyl & $\varnothing$, open & 196.915 & 27.754 & 171.110 & 7.095 & $3.28 \mathrm{e}-11$ & $* * *$ \\
\hline VowSyl & $\mathbf{a}$, closed & 138.107 & 16.736 & 197.049 & 8.252 & $2.20 \mathrm{e}-14$ & $* * *$ \\
\hline VowSyl & $\mathbf{a}$, open & 284.699 & 27.754 & 171.110 & 10.258 & $<2 \mathrm{e}-16$ & $* * *$ \\
\hline VowSyl & o, closed & 112.090 & 15.402 & 225.208 & 7.278 & $5.61 e-12$ & $* * *$ \\
\hline VowSyl & o, open & 163.584 & 26.869 & 196.352 & 6.088 & $5.90 e-09$ & $* * *$ \\
\hline VowSyl & $œ$, closed & 262.454 & 17.762 & 209.989 & 14.776 & $<2 e-16$ & $* * *$ \\
\hline VowSyl & œ, open & 232.068 & 27.754 & 171.110 & 8.362 & $2.08 \mathrm{e}-14$ & $* * *$ \\
\hline VowSyl & a, closed & 199.455 & 15.765 & 200.540 & 12.652 & $<2 e-16$ & $* * *$ \\
\hline VowSyl & $\mathrm{a}$, open & 300.431 & 27.765 & 171.395 & 10.820 & $<2 e-16$ & $* * *$ \\
\hline VowSyl & $\varepsilon$, closed & 240.647 & 12.811 & 642.263 & 18.784 & $<2 \mathrm{e}-16$ & $* * *$ \\
\hline VowSyl & $\varepsilon$, open & 199.726 & 27.778 & 171.696 & 7.190 & $1.91 \mathrm{e}-11$ & $* * *$ \\
\hline VowSyl & I, closed & 237.386 & 15.596 & 208.796 & 15.221 & $<2 \mathrm{e}-16$ & $* * *$ \\
\hline VowSyl & i, open & 232.350 & 25.510 & 273.225 & 9.108 & $<2 e-16$ & $* * *$ \\
\hline VowSyl & Y, closed & 251.157 & 15.766 & 200.610 & 15.931 & $<2 e-16$ & $* * *$ \\
\hline VowSyl & $\mathrm{y}$, open & 226.214 & 27.777 & 171.693 & 8.144 & $7.55 e-14$ & $* * *$ \\
\hline VowSyl & u, closed & 248.346 & 15.700 & 204.474 & 15.819 & $<2 e-16$ & *** \\
\hline VowSyl & $\mathrm{u}$, open & 248.152 & 27.802 & 172.302 & 8.926 & $6.43 e-16$ & *** \\
\hline VowSyl & o, closed & 201.418 & 15.511 & 215.905 & 12.985 & $<2 e-16$ & $* * *$ \\
\hline VowSyl & e, open & 167.663 & 27.754 & 171.110 & 6.041 & $9.28 \mathrm{e}-09$ & $* * *$ \\
\hline Sex & M & 60.435 & 8.725 & 560.089 & 6.927 & $1.18 \mathrm{e}-11$ & *** \\
\hline VowSyl|*Sex & ø, closed, M & -73.860 & 17.171 & 8619.924 & -4.301 & $1.72 e-05$ & $* * *$ \\
\hline VowSy|*Sex & ø, open, M & -40.731 & 17.325 & 8612.244 & -2.351 & 0.018745 & $*$ \\
\hline VowSyl*Sex & $\mathbf{a}$, closed, M & -39.032 & 10.901 & 8614.369 & -3.581 & 0.000345 & $* * *$ \\
\hline VowSy|*Sex & a, open, M & -46.737 & 17.325 & 8612.244 & -2.698 & 0.006996 & $* *$ \\
\hline VowSy|*Sex & o, closed, M & -43.550 & 10.344 & 8615.764 & -4.210 & $2.58 \mathrm{e}-05$ & *** \\
\hline VowSy|*Sex & o, open, M & -20.096 & 17.327 & 8615.151 & -1.160 & 0.246162 & \\
\hline VowSyl*Sex & œ, closed, M & -59.732 & 11.809 & 8614.949 & -5.058 & $4.32 \mathrm{e}-07$ & $* * *$ \\
\hline VowSy|*Sex & œ, open, M & -34.551 & 17.325 & 8612.244 & -1.994 & 0.046153 & $*$ \\
\hline VowSy|*Sex & $\mathrm{a}$, closed, M & -44.751 & 10.313 & 8615.541 & -4.339 & $1.45 e-05$ & $* * *$ \\
\hline VowSy|*Sex & $\mathrm{a}$, open, M & -38.825 & 17.344 & 8612.309 & -2.239 & 0.025209 & $*$ \\
\hline VowSyl*Sex & $\varepsilon$, closed, M & -53.612 & 10.411 & 8617.576 & -5.150 & $2.67 e-07$ & $* * *$ \\
\hline VowSy|*Sex & $\varepsilon$, open, M & -39.453 & 17.363 & 8612.596 & -2.272 & 0.023094 & $*$ \\
\hline VowSy|*Sex & I, closed, M & -49.939 & 10.332 & 8615.770 & -4.834 & $1.36 e-06$ & *** \\
\hline VowSy|*Sex & i, open, M & -26.238 & 17.556 & 8649.277 & -1.495 & 0.135068 & \\
\hline VowSyl*Sex & Y, closed, M & -52.350 & 10.321 & 8614.677 & -5.072 & $4.01 \mathrm{e}-07$ & $* * *$ \\
\hline VowSyl*Sex & y, open, M & -31.606 & 17.478 & 8613.067 & -1.808 & 0.070592 & . \\
\hline VowSy|*Sex & U, closed, M & -53.870 & 10.318 & 8614.766 & -5.221 & $1.82 \mathrm{e}-07$ & *** \\
\hline VowSyl|*Sex & $\mathrm{u}$, open, $\mathrm{M}$ & -69.773 & 17.632 & 8613.165 & -3.957 & $7.65 e-05$ & $* * *$ \\
\hline VowSy|*Sex & o, closed, M & -50.467 & 10.293 & 8616.684 & -4.903 & $9.60 \mathrm{e}-07$ & $* * *$ \\
\hline VowSyl|*Sex & e, open, M & -20.619 & 17.439 & 8612.650 & -1.182 & 0.237100 & \\
\hline
\end{tabular}


Table B3 Model summary for F2 dynamics.

\begin{tabular}{|c|c|c|c|c|c|c|c|}
\hline & & Estimate & Std. error & d.f. & $t$-value & $\operatorname{pr}(>|t|)$ & Sig. \\
\hline Intercept & & 538.19 & 25.60 & 244.52 & 21.021 & $<2 e-16$ & $* * *$ \\
\hline VowSyl & $\varnothing$, closed & -322.40 & 52.52 & 319.64 & -6.139 & $2.46 \mathrm{e}-09$ & $* * *$ \\
\hline VowSyl & Ø, open & -386.63 & 69.51 & 160.96 & -5.562 & $1.09 e-07$ & $* * *$ \\
\hline VowSyl & $\mathbf{a}$, closed & -535.95 & 40.60 & 190.11 & -13.201 & $<2 e-16$ & $* * *$ \\
\hline VowSyl & $\mathrm{a}$, open & -603.88 & 69.51 & 160.96 & -8.687 & $4.00 e-15$ & $* * *$ \\
\hline VowSyl & o, closed & -618.02 & 36.17 & 233.57 & -17.089 & $<2 \mathrm{e}-16$ & *** \\
\hline VowSyl & o, open & -563.34 & 64.49 & 217.82 & -8.735 & $6.53 e-16$ & $* * *$ \\
\hline VowSyl & $œ$, closed & -634.64 & 42.65 & 196.10 & -14.881 & $<2 e-16$ & *** \\
\hline VowSyl & œ, open & -572.29 & 69.51 & 160.96 & -8.233 & $5.93 e-14$ & $* * *$ \\
\hline VowSyl & a, closed & -442.20 & 38.14 & 191.38 & -11.594 & $<2 \mathrm{e}-16$ & $* * *$ \\
\hline VowSyl & $\mathrm{a}$, open & -469.81 & 69.51 & 160.96 & -6.758 & $2.43 e-10$ & $* * *$ \\
\hline VowSyl & $\varepsilon$, closed & -643.95 & 24.84 & 1664.94 & -25.928 & $<2 e-16$ & *** \\
\hline VowSyl & $\varepsilon$, open & -514.49 & 69.53 & 161.07 & -7.400 & $7.12 e-12$ & $* * *$ \\
\hline VowSyl & I, closed & -668.59 & 37.42 & 198.88 & -17.866 & $<2 \mathrm{e}-16$ & $* * *$ \\
\hline VowSyl & $\mathrm{i}$, open & -666.58 & 57.26 & 348.01 & -11.640 & $<2 e-16$ & $* * *$ \\
\hline VowSyl & Y, closed & -644.09 & 38.14 & 191.61 & -16.888 & $<2 \mathrm{e}-16$ & *** \\
\hline VowSyl & $\mathrm{y}$, open & -581.22 & 69.59 & 161.69 & -8.352 & $2.88 \mathrm{e}-14$ & $* * *$ \\
\hline VowSyl & u, closed & -342.92 & 37.76 & 200.41 & -9.082 & $<2 \mathrm{e}-16$ & $* * *$ \\
\hline VowSyl & $\mathrm{u}$, open & -418.52 & 69.59 & 161.69 & -6.014 & $1.17 e-08$ & $* * *$ \\
\hline VowSyl & $\boldsymbol{0}$, closed & -424.93 & 36.79 & 219.02 & -11.551 & $<2 e-16$ & $* * *$ \\
\hline VowSyl & e, open & -450.54 & 69.54 & 161.19 & -6.479 & $1.07 e-09$ & $* * *$ \\
\hline Sex & M & -142.19 & 13.85 & 752.48 & -10.266 & $<2 \mathrm{e}-16$ & $* * *$ \\
\hline VowSy|*Sex & $\varnothing$, closed, M & 104.32 & 28.11 & 8597.49 & 3.711 & 0.000208 & *** \\
\hline VowSy|*Sex & $ø$, open, M & 114.54 & 28.33 & 8590.16 & 4.043 & $5.32 e-05$ & $* * *$ \\
\hline VowSy|*Sex & $\mathbf{a}$, closed, M & 137.87 & 17.82 & 8592.04 & 7.736 & $1.15 e-14$ & $* * *$ \\
\hline VowSy|*Sex & a, open, M & 132.84 & 28.33 & 8590.16 & 4.689 & $2.79 e-06$ & $* * *$ \\
\hline VowSy|*Sex & o, closed, M & 124.05 & 16.92 & 8593.99 & 7.334 & $2.44 \mathrm{e}-13$ & $* * *$ \\
\hline VowSy|*Sex & o, open, M & 158.61 & 28.33 & 8595.65 & 5.598 & $2.24 \mathrm{e}-08$ & $* * *$ \\
\hline VowSy|*Sex & œ, closed, M & 192.55 & 19.31 & 8592.62 & 9.972 & $<2 \mathrm{e}-16$ & $* * *$ \\
\hline VowSy|*Sex & œ, open, M & 146.60 & 28.33 & 8590.16 & 5.175 & $2.33 e-07$ & $* * *$ \\
\hline VowSy|*Sex & a, closed, M & 107.03 & 16.86 & 8594.27 & 6.349 & $2.28 \mathrm{e}-10$ & $* * *$ \\
\hline VowSy|*Sex & a, open, M & 148.14 & 28.33 & 8590.16 & 5.229 & $1.74 \mathrm{e}-07$ & $* * *$ \\
\hline VowSy|*Sex & $\varepsilon$, closed, M & 173.46 & 17.02 & 8595.48 & 10.191 & $<2 e-16$ & $* * *$ \\
\hline VowSy|*Sex & $\varepsilon$, open, M & 142.06 & 28.36 & 8590.21 & 5.009 & $5.57 e-07$ & $* * *$ \\
\hline VowSy|*Sex & I, closed, M & 182.54 & 16.89 & 8593.79 & 10.805 & $<2 \mathrm{e}-16$ & $* * *$ \\
\hline VowSy|*Sex & i, open, M & 206.76 & 29.13 & 8628.81 & 7.097 & $1.37 e-12$ & $* * *$ \\
\hline VowSy|*Sex & Y, closed, M & 177.33 & 16.87 & 8592.39 & 10.509 & $<2 e-16$ & $* * *$ \\
\hline VowSy|*Sex & y, open, M & 159.17 & 28.71 & 8591.08 & 5.544 & $3.04 e-08$ & $* * *$ \\
\hline VowSyl|*Sex & U, closed, M & 95.05 & 16.88 & 8592.64 & 5.632 & $1.84 \mathrm{e}-08$ & $* * *$ \\
\hline VowSy|*Sex & u, open, M & 141.13 & 28.70 & 8590.64 & 4.917 & $8.93 e-07$ & $* * *$ \\
\hline VowSy|*Sex & o, closed, M & 95.03 & 16.83 & 8595.43 & 5.647 & $1.69 \mathrm{e}-08$ & $* * *$ \\
\hline VowSy|*Sex & e, open, M & 180.56 & 28.39 & 8590.28 & 6.360 & $2.12 e-10$ & $* * *$ \\
\hline
\end{tabular}

VowSyl = vowel, type of syllable; $M=$ male

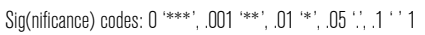

F2_dyn $\sim$ VowSyl $*$ Sex $+(1 \mid$ Speaker $)+(1 \mid$ Task:Word $)$ 


\section{References}

Avanzi, Mathieu. 2018. Cartographier les régionalismes du français en Suisse romande et en France voisine à l'ère des sciences participatives. Cahiers internationaux de sociolinguistique 2(14), 43-103.

Bates, Douglas, Martin Maechler, Ben Bolker \& Steve Walker. 2015. Fitting linear mixed-effects models using lme4. Journal of Statistical Software 67(1), 1-48.

Boersma, Paul \& David Weenink. 2019. Praat: Doing phonetics by computer (version 6.1.x). http://www.praat.org/ (downloaded 15 December 2019).

Côté, Marie-Hélène. 2010. La longueur vocalique devant consonne allongeante en contexte final et dérivé en français laurentien. In Carmen LeBlanc, France Martineau \& Yves Frenette (eds.), Vues sur les français d'ici, 49-75. Québec: Presses de l'Université Laval.

Côté, Marie-Hélène. 2012. Laurentian French (Quebec): Extra vowels, missing schwas and surprising liaison consonants. In Randall Gess, Chantal Lyche \& Trudel Meisenburg (eds.), Phonological variation in French: Illustrations from three continents, 235-274. Amsterdam: John Benjamins.

Côté, Marie-Hélène \& Mélanie Lancien. 2019. The / $/ /-/ 3 /$ contrast in Quebec French. In Sasha Calhoun, Paola Escudero, Marija Tabain \& Paul Warren (eds.), 19th International Congress of Phonetic Sciences (ICPhS XIX), Melbourne, 1530-1534.

Delattre, Pierre. 1963. Voyelles diphtonguées et voyelles pures. The French Review 37(1), 64-76.

Dolbec, Jean \& Conrad Ouellon. 1999. Peut-on distinguer des variétés phonétiques en français québécois? Dialangue 10, 17-28.

Dumas, Denis. 1974. Durée vocalique et diphtongaison en français québécois. Cahier de linguistique 4, $13-55$.

Dumas, Denis. 1981. Structure de la diphtongaison québécoise. Revue canadienne de linguistique 26(1), $1-61$.

Dumas, Denis. 1987. Nos façons de parler: les prononciations en français québécois. Québec: Presses de l’Université du Québec.

Durand, Jacques, Bernard Laks \& Chantal Lyche. 2009. Le projet PFC (phonologie du français contemporain): une source de données primaires structurées. In Jacques Durand, Bernard Laks \& Chantal Lyche (eds.), Phonologie, variation et accents du français, 19-61. Paris: Hermès.

Fougeron, Cécile \& Caroline L. Smith. 1993. French. Journal of the International Phonetic Association 23(2), 73-76.

Gottfried, Terry L. 1984. Effects of consonant context on the perception of French vowels. Journal of Phonetics 12(2), 91-114.

Kuznetsova, Alexandra, Per B. Brockhoff \& Rune H. B. Christensen. 2017. lmerTest package: Tests in linear mixed effects models. Journal of Statistical Software 82(13), 1-26.

Leblanc, Guillaume. 2012. Une étude acoustique des voyelles orales susceptibles d'être diphtonguées en français québécois. Master's thesis, Université Laval.

Lehiste, Ilse \& Gordon E. Peterson. 1961. Transitions, glides, and diphthongs. The Journal of the Acoustical Society of America 33(3), 268-277.

Lenth, Russell, Jonathon Love \& Maxime Herve. 2018. emmeans: Estimated marginal means, aka least-squares means ( $\mathrm{R}$ package version 1.1.2). http://CRAN-R-project.org/package=emmeans/ (downloaded 15 December 2019).

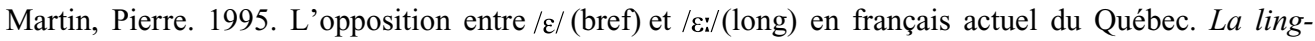
uistique 31(2), 33-45.

Martin, Pierre. 1996. Éléments de phonétique avec application au français. Québec: Presses de l'Université Laval.

Martin, Pierre. 2002. Le système vocalique du français du Québec: de l'acoustique à la phonologie. $L a$ linguistique 38(2), 71-88.

Martinet, André. 1958. 'C'est jeuli, le Mareuc!' Romance Philology 11(4), 345-355.

Martinet, André. 1969. Le français sans fard. Paris: Presses universitaires de France.

Ménard, Lucie. 2002. Production et perception des voyelles au cours de la croissance du conduit vocal: Variabilité, invariance et normalisation. Ph.D. dissertation, Université Stendhal Grenoble III. 
Morin, Yves-Charles. 2009. Á propos de la fermeture des voyelles moyennes devant [r] dans le français du Québec. Revue canadienne de linguistique 54(3), 461-510.

Morin, Yves-Charles \& Martine Ouellet. 1991. Les [ $\varepsilon$ ] longs devant [s] en français: sources historiques et évolution. Revue québécoise de linguistique 20(2), 11-32.

Morrison, Geoffrey Stewart \& Peter F. Assmann (eds.). 2013. Vowel inherent spectral change. Berlin \& Heidelberg: Springer.

Nearey, Terrance M. \& Peter F. Assmann. 1986. Modeling the role of inherent spectral change in vowel identification. The Journal of the Acoustical Society of America 80(5), 1297-1308.

Paradis, Claude \& Jean Dolbec. 1998. PHONO: les principales caractéristiques phonétiques du français parlé au Québec. http://phono.uqac.ca/ (consulted 15 December 2019).

R Core Team. 2019. R: A language and environment for statistical computing. https://www.r-project.org/ (downloaded 15 December 2019).

Reinke, Kristin. 2005. La langue à la télévision québécoise: aspects sociophonétiques. Québec: Office québécois de la langue française.

Santerre, Laurent. 1971. Les voyelles orales dans le français parlé à Montréal. Ph.D. dissertation, Université des Sciences humaines de Strasbourg.

Santerre, Laurent. 1974. Deux E et deux A phonologiques en français québécois: étude phonologique, articulatoire et acoustique des oppositions de timbre et de durée. Cahier de linguistique 4, 117-145.

Santerre, Laurent. 1981. Stabilité et variation des oppositions $\varepsilon / 3$ et a/a en français de Montréal. Logos Semantikos 5, 375-384.

Santerre, Laurent \& Jean Millo. 1978. Diphthongization in Montreal French. In David Sankoff (ed.), Linguistic variation: Models and methods, 173-184. New York: Academic Press.

Squair, John. 1888. A contribution to the study of Franco-Canadian dialect. Proceedings of the Canadian Institute 6, 161-168.

St-Gelais, Xavier. 2019. L'antériorisation de /o/ en français contemporain: une étude acoustique comparative entre Québec et France. Master's thesis, Université du Québec à Chicoutimi.

Straka, Georges. 1959. Durée et timbre vocaliques: observations de phonétique générale, appliquées à la phonétique historique des langues romanes. Zeitschrift für Phonetik und allgemeine Sprachwissenschaft 12(1), 276-300.

Walker, Douglas C. 1984. The pronunciation of Canadian French. Ottawa: University of Ottawa Press.

Walter, Henriette. 1982. Enquête phonologique et variétés régionales du français. Paris: Presses universitaires de France.

Yaeger-Dror, Malcah. 1994. Phonetic evidence for sound change in Quebec French. In Patricia A. Keating (ed.), Phonological structure and phonetic form: Papers in Laboratory Phonology III, 267-292. Cambridge: Cambridge University Press.

Yaeger-Dror, Malcah \& William Kemp. 1992. Lexical classes in Montreal French: The case of (ع:). Language and Speech 35(3), 251-293. 